This document is the author's version of an accepted manuscript of a published work that appeared in final form in The Gerontologist, copyright (C) Oxford University Press after peer review and technical editing by the publisher. To access the final edited and published work see [https://doi.org/10.1093/geront/gnx175].

\title{
Carers as System Navigators: Exploring sources, processes and outcomes of structural burden
}

Funk, L.M.1, Dansereau, L.1, and Novek, S.2

1. 183 Dafoe Road, Isbister Building, University of Manitoba, Winnipeg, Manitoba, Canada R3T2N2

2. Department of Community Health Sciences, Max Rady College of Medicine, University of Manitoba, Winnipeg, Manitoba

\section{Funding/Acknowledgements}

This research was supported by an Establishment Award from Research Manitoba. We greatly appreciate the time and contributions of our carer participants, research assistants Erin Scott and Wanda Hounslow, and professional transcriptionist Catherine Davey.

\begin{abstract}
Background and Objectives. Structural features of formal care systems influence the amount, difficulty and complexity of what carers do as they interface with those systems. In this study we explored how carers navigate health and social care systems, and their experiences of structural burden related to features such as complexity and fragmentation.
\end{abstract}

Research Design and Methods. This qualitative descriptive inquiry drew on data from in-person interviews with 32 carers of older adults, which were analyzed first using inductive thematic analysis and then using structural burden as a conceptual lens.

Results. Participant accounts revealed how navigating formal systems on behalf of older adult family members can exact considerable demands on carers in terms of time investment and emotional energy. In this way, care systems exacerbate the stress and structural burden experienced by carers, even when formal services alleviate other forms of carer burden.

Discussion and Implications. Our findings contribute to knowledge of how the structural context of formal services shapes carer experiences and outcomes. To promote equity and prevent burden, system navigation work should be considered as a public, structural issue, rather than an individual-level problem of skills and learning.

KEYWORDS: Access to and utilization of services; care coordination; caregiving informal; qualitative analysis - thematic analysis 
This document is the author's version of an accepted manuscript of a published work that appeared in final form in The Gerontologist, copyright (C) Oxford University Press after peer review and technical editing by the publisher. To access the final edited and published work see [https://doi.org/10.1093/geront/gnx175].

\section{Introduction}

Family and friends make considerable care contributions as older adults access formal health services (Penning, 2002). Conceptualizations of family care as occurring in the private realm do not reflect the work families are required to do in the context of fragmented and limited formal services, and traditional demarcations between formal and family care are increasingly contested (Armstrong \& Armstrong, 2005; Bookman \& Harrington, 2007). Families work within and between institutional and community settings to facilitate care, as managers, record-keepers, pseudo-paramedics, and advocates (Bookman \& Harrington, 2007). Empirical and theoretical inquiry is needed to understand how formal care structures contribute to carer burden (Taylor \& QuesnelVallée, 2017). This study examines how family carers navigate formal services with and for older adults.

The concept of system navigation originated out of concern for health care equity and access among disadvantaged groups of patients. The term tends to be used to describe professional support intended to reduce barriers to accessing care (Dohan \& Schrag, 2005; Manderson et al., 2012). However, when formal system navigators are unavailable or lack the resources to help connect families with services, this work falls to family carers.

Previous research has incorporated some limited attention to carers' navigational work. For instance, Wuest (2000) explored how negotiating with formal services may become easier as carers develop expertise and confidence. Navigation also aligns with the concept of care management, which includes accessing and monitoring formal services, advocating with formal providers, and coordinating informal support (Rosenthal et al. 2007). In existing caregiving research, the dearth of in-depth information on navigational work is notable in comparison to other aspects of care, despite the fact that system navigation has been identified as an important concern and an unmet need (Farran et al., 2004; Funk, Stajduhar \& Outcalt, 2015; Funk, 2012; Williams et al. 2010; MartinezDonate et al., 2013).

The complexity of system navigation is compounded when services are fragmented, excessively bureaucratic, and uncoordinated (Bookman \& Harrington, 2007; Koehn, 2009; Ravenscroft, 2010; Taylor \& Quesnel- Vallée, 2017). The effort required to secure services can hinder access, generating inequities among patients (Dixon Woods et al., 2006), and may also contribute to negative carer outcomes, although there has been little research in this area. System navigation challenges may lead to interpretations of systems as "impersonal and even hostile" (Schubart, Kinzie \& Farace, 2008; p.67). In contrast, assistance with system navigation may be important for feeling supported, respected, and recognized by formal providers (Funk, 2012).

The impacts of care management include stress, employment costs and other personal costs (Rosenthal, Martin-Matthews \& Keefe, 2007). Taylor and Quesnel-Vallée (2017) proposed the concept of structural burden as a distinct form of carer burden stemming from "managing complex interactions with the fragmented structures of formal health and social care systems" (p.2). Their work highlights the need for definitions and 
This document is the author's version of an accepted manuscript of a published work that appeared in final form in The Gerontologist, copyright (C) Oxford University Press after peer review and technical editing by the publisher. To access the final edited and published work see [https://doi.org/10.1093/geront/gnx175].

measures of carer burden that include the effort involved in navigational work, and calls for policy evaluations that incorporate structural burden when modeling outcomes.

There is growing evidence that system navigation constitutes a key component of carer work, with potential consequences for carer well-being. However, we know little about how this work is conducted, under what conditions, how it is experienced by carers, and how it might be connected to burden. The present study uses the analytic lens of structural burden to examine how carers of older adults in one Canadian province navigate formal health and social services.

In Canada, provinces oversee the delivery of medical services through universal insurance, as determined by the 1984 Canada Health Act. Provinces are also responsible for delivering in-home services and social programs, which lie outside the scope of the Canada Health Act. Service availability and accessibility varies widely between provinces; typically, some portion of the cost of home and residential care for older adults is provincially insured, and is delivered through a combination of public, not-forprofit, and for-profit service providers. However, reductions in federal transfers have created a climate of economic scarcity, leading to service rationing, user-fees, meanstesting, and an increasing reliance on for-profit models of care.

\section{Design and Methods}

In the absence of an in-depth understanding of either structural burden or system navigation, qualitative inquiry is indicated for an exploration of these complex social phenomena and processes. Following approval from the university ethics board, 32 carers in Winnipeg, Canada provided written consent to participate in in-depth, in-person interviews. Data was first examined using inductive thematic analysis, and later guided by the analytic lens of structural burden.

\section{Participants}

To reach as broad range of carers as possible, participants were recruited through a media release, advertisements in local papers, posters in community and seniors' centres and through local carer organizations. Criterion sampling techniques ensured that all participants belonged to our population of interest (carers with system navigation experience), while also recruiting "information-rich cases" (Patton, 1990: p.169). We solicited carers defined broadly as those providing unpaid support, including help with system navigation, to one or more older adults (aged 65+) facing age-related mental or physical challenges. Family was defined broadly, and included friends (aligning with contemporary understandings of care). Eligible participants were legal adults with conversational English-language familiarity. Recruitment ceased when the team reached consensus regarding the level of saturation of inductive findings. All but two participants had at least some post-secondary education, and roughly $80 \%$ were Caucasian middleclass women, as indicated in Table 1. 
This document is the author's version of an accepted manuscript of a published work that appeared in final form in The Gerontologist, copyright (C) Oxford University Press after peer review and technical editing by the publisher. To access the final edited and published work see [https://doi.org/10.1093/geront/gnx175].

\section{***TABLE 1 ABOUT HERE****}

\section{Procedures}

In-depth, in-person interviews were conducted between October 2014 and May 2015 by each of the authors and a research assistant. The interview guide consisted of open-ended questions designed to elicit accounts of experiences navigating formal services. Participants were asked questions such as "What would you say is the biggest struggle for you in helping your loved one?" and "Can you talk about a time when you helped your loved one navigate through an organization, system or bureaucracy?" Probes and prompts encouraged detailed examples and elaboration, and data quality was assessed during the analysis of the first few transcripts. In an iterative manner common in qualitative research, minor modifications (such as introducing additional probes) were made to subsequent interview guides after the first few interviews, to facilitate discovery. The average length of interviews was 93 minutes, ranging from 23 to 138 minutes. Audio-recordings were professionally transcribed in verbatim form.

\section{Analysis}

Our analysis was directed by two key objectives: a) to inductively examine carers' experiences navigating systems; and b) to use structural burden as an analytic lens, so as to explore the causes and consequences of structural burden. First, transcripts were analyzed thematically (Braun \& Clarke, 2006; Vaismoradi et al., 2013) by the first and second authors with the aid of NVivo software. Each author read all data to first identify a preliminary list of themes related to system navigation. Data-reduction techniques helped to condense and summarize the contextual information and latent meanings, and visual diagramming was used to explore connections between themes. Regular team meetings facilitated discussion about thematic and participant variation, and a coding scheme was developed and refined through reiterative comparison. Our resulting themes focused largely on the work involved in navigating systems. We then applied the concept of structural burden as a lens with which to target and refine our analysis to examine the structural features and outcomes associated with system navigation.

\section{Results}

\section{Forms of Navigational Work by Carers}

In our inductive examination of carers' accounts of interacting with formal systems, we identified three forms of navigational work: learning about services and resources, trying to secure access to services, and coordinating and overseeing the smooth and effective provision of those services.

Navigating the mystery: digging and hunting. This first step of system navigation entailed learning about the available services and figuring out how to access them. Much of this work occurred early in caring careers, although information needs continued to emerge as carers tried to secure new, different, more appropriate or better quality services. Participants frequently described investing efforts in digging and hunting for 
This document is the author's version of an accepted manuscript of a published work that appeared in final form in The Gerontologist, copyright (C) Oxford University Press after peer review and technical editing by the publisher. To access the final edited and published work see [https://doi.org/10.1093/geront/gnx175].

information - calling around, asking questions, searching the internet, and relying on informal networks. For instance, one daughter explained:

I'm the kind of person that asks a lot of questions... So I really have been good at asking. I can find anything if I need to find it. I just keep asking ... If you know it's out there you ask until you find it and if you don't know that it's out there you keep asking.

Vague and conflicting information complicated navigational work; for instance, one carer explained how her understanding of nursing home access was hampered because the process was not understood in the same way even by people working within the system. Thus she received conflicting information from multiple sources.

Being resourceful was imperative for gathering information, privileging those who were persistent, confident at asking questions, and adept at utilizing social networks and the internet for information. Two well-resourced participants also hired private consultants for help in this regard. Several participants expressed concern for less advantaged carers, as when one daughter stated:

How do you navigate it when you're by yourself? How do you navigate it when you're not at ease making six phone calls or you can't figure out how to do it or you don't have access to a computer in your home so that you can go online and figure it out? It's so not transparent and because of its not being transparent it's so inequitable.

Previous caregiving experience or system knowledge did not always guarantee advantage. For example, one participant described the complicated nursing home system: "having done it with my mom and then trying to do it with my friends it's different. Every case is so different." Further, when a change in the care recipient or carer's status precipitated an emergent need for new services, informational challenges often resurfaced for even the most experienced carers.

Many participants indicated that service providers played important roles in providing resource information, yet identifying these key formal providers was sometimes difficult, and entailed learning how information flows through services. Carers most commonly obtained information through informal social networks, often characterizing this as more productive than interactions with service providers or selfinitiated research. In some cases information was acquired based on an active process of asking others for advice, but some participants also expressed that much of their knowledge was acquired serendipitously. Several also eventually became advisors or mentors to other carers in their networks. One experienced carer, for instance, noted:

It's unbelievable how people find you. Even here [at my workplace], we have 140 staff, about 8 of them have gone through the same thing and as soon as they find out that somebody has to be 
This document is the author's version of an accepted manuscript of a published work that appeared in final form in The Gerontologist, copyright (C) Oxford University Press after peer review and technical editing by the publisher. To access the final edited and published work see [https://doi.org/10.1093/geront/gnx175].

[waitlisted for a nursing home], they're in my office because somebody told them go see me. I've had four colleagues whose parents have been [waitlisted] and gone through all sort of barriers and so they called me... they talk to you about - where to go, what to do, who to see...

Navigating barriers: pushing through and working around. In trying to navigate access at the point of entry to services, participants frequently described encounters with gatekeeping, inflexible policies, restrictive eligibility criteria, long wait times, and problematic assessment and application procedures. These carers explained how, as a result, they had to push through or work around systems to access support for their family member. These struggles did not necessarily end once a service was initially accessed, as entry to different types of services often necessitated additional work.

Convoluted application and approval processes were cited by several participants; for instance, one carer described obtaining compression stockings for her grandmother:

I was supposed to get the compression stockings. Well you need the referral, but you don't need this and you need that and you're constantly going in one big circle because homecare didn't want to be responsible, and then you wouldn't get what you needed because it was a walk-in doctor and not a regular doctor, and then you had to go and get the pressure tension done to make sure that the skin could handle it. So you couldn't go and just fill the prescription for the stockings.

Application processes were often characterized as complex, overwhelming and intimidating; for example, another granddaughter describes her experience of applying for a federal caregiver tax credit:

I looked it up. I did all the phone calls and I have the paperwork and it's with the [regional health agency] and even then it takes forever, 8 weeks or something, and then they have to agree to it. .... [the tax credit will] be really great, but it's taking forever. I had to make an appointment with [grandmother's] doctor to have her doctor fill it out and I go there and [the doctor] says, 'where's your grandmother'? I'm like, 'you guys never said I had to bring her.' ...I'm like, why didn't anyone tell me this when I booked the appointment four weeks ago, and really explained in detail why I was coming down? I needed the doctor to claim that 'yes you take care of her' and that's it. Sitting there I'm like 'oh my God this is going to take forever.' I don't understand what the problem is. It just seems very frustrating.

The participant's experience of the application procedure was exacerbated by her lack of process information.

Some participants also described key formal providers who failed to make referrals or assessments so that the older adult could access supports. For example, one carer explained that her mother had severe anxiety and cognitive impairment, and needed someone to be constantly present at home. The home care coordinator told her "we're not here to babysit", and when the participant asked about receiving respite services so that 
This document is the author's version of an accepted manuscript of a published work that appeared in final form in The Gerontologist, copyright (C) Oxford University Press after peer review and technical editing by the publisher. To access the final edited and published work see [https://doi.org/10.1093/geront/gnx175].

she could have a break, the coordinator replied that the service was difficult to book. The carer added: "every time you ask something she's so negative. She shuts you down."

Overall, most carers characterized the work required to actually access services using terms such "struggling," "pushing," "pulling teeth," "lobbying," "negotiating," and "fighting." However, not all participants experienced challenges in accessing care in all situations. For instance, one co-resident carer explained that her own mobility challenges meant that she needed help with housecleaning. She suggested to the homecare coordinator that she herself be assessed for service, but by the next week housecleaning had been added to the list of support services in her husband's case file.

In contrast, several other carers actively and persistently engaged in advocacy to gain entry to services; some even contacted elected officials, facility administrators, and government representatives to help their family member acquire access to a particular resource. Several participants also believed that some carers are better equipped to advocate in this way; they spoke of self-motivation, confidence, experience, persistence, and not being afraid to challenge authority or to 'bother' professionals. One participant reflected on the root problem after describing how she overcame barriers to access:

I'm not very interested in opening doors that only [we] can get through. The whole idea is to blast open the doors because there's a problem with the doors.

Other carers tried to work around systems when they faced barriers, employing tacit knowledge and creativity. For instance, one daughter, dissatisfied with her mother's doctor, had a difficult time finding a doctor accepting new patients. One office told her they were accepting new patients, but had a policy of not accepting patients who already had a doctor. The participant made an appointment on behalf of a different relative and accompanied her to the appointment. This gave her the chance to speak directly to the doctor, who agreed to accept her mother with a referral.

Navigating fragmentation: coordination and oversight of services. As older adults became successfully connected to formal services, carers' navigational work assumed yet another form - coordinating services and ensuring that care flows smoothly and effectively meets needs. Indeed, the onus appeared to be on carers to link together formal systems and services (as well as informal sources of help), and store relevant knowledge about the care recipient. This role was particularly important during times of transition for the care recipient, and was especially difficult when the carer also faced personal challenges, because of its unrelenting nature. For instance, one spousal carer with physical disabilities waited a year for surgery for a broken shoulder, and explained how she found it difficult to "maneuver" and coordinate the system for both herself and her husband: "there I was on the phone with a broken shoulder for hours split into here and there, phoning the doctor and the occupational therapist and the homecare and ... because I was the only one that had the Power of Attorney or knew what was happening." Although the participant characterizes this as an unforeseen and unavoidable 
This document is the author's version of an accepted manuscript of a published work that appeared in final form in The Gerontologist, copyright (C) Oxford University Press after peer review and technical editing by the publisher. To access the final edited and published work see [https://doi.org/10.1093/geront/gnx175].

circumstance, her experience illuminates how existing systems may not function well at accommodating complications in carers' lives.

When systems were unresponsive to developing needs of older adults, carers often assumed responsibility to alert formal providers to these changes. Some carers also took on the work of 'prompting' service providers to help formal systems function smoothly. For example, one carer's cited the "constant thinking" involved in this work: her husband required frequent blood tests, and was normally phoned with results, "but if I hadn't heard in three days I'd have to remember. 'Ah...I wonder what his [test result] was?' And phone them and get it."

Uncoordinated bureaucratic systems further required carers to comply with what they perceived as excessive administrative demands, essentially working for these systems. For instance, one participant described some of the annual paperwork she was required to submit. First she would provide her father's nursing home with his tax returns for an income-based fee assessment funded by the province. Following this she would forward the information on to Veteran's Affairs, a federal government department, which pays provincial governments a portion of nursing home costs. When contacting various departments regarding errors (which occurred frequently), she was never given a consistent contact person and had to reiterate her father's case history each time. She faced similar administrative issues for reimbursement of other expenses, and chose not to try to recoup the costs of smaller purchases, saying "it's not worth my time. You have to pick your battles."

This participant, and many others, also explained how they needed to be organized and diligent in documentation to coordinate and monitor care. Another carer, for instance, kept detailed notes, including lists of formal care contacts, records of meetings, and information received from various providers:

\footnotetext{
You have to really associate a lot of information. The social worker actually offered me a job at the hospital. They said 'we think that you should be a professional advocate.' (Laughs) Because, they said, 'nobody has ever tried to worm around something but they can't with you' because I had things documented from this social worker to that one. Then I would be able to say 'we met on this day and we went over this' and then, knowing the nurse, say 'that person is supposed to give [medication] at 7:00. Well I'm here and they're giving it at 10:30. Now she's in extreme pain.' That's where the accountability starts coming in and so it's a lot of dedication and then lots of organizing. And you don't want to be constantly like that but you need to be when you're dealing with the different systems.
}

Several carers also specifically suggested that they learned over time that services could not always be trusted to meet care recipients' needs. One carer, for example, noted: "I was just trusting that... I was letting the system just unfold and I realize now that you can't do that." System distrust tended to have implications for carers' service satisfaction, their overall experience of caregiving, and required carers to spend additional time and energy overseeing the function of existing services. For instance, one daughter explained how her mother, who did not have dementia, was to be temporarily placed in a locked 
This document is the author's version of an accepted manuscript of a published work that appeared in final form in The Gerontologist, copyright (C) Oxford University Press after peer review and technical editing by the publisher. To access the final edited and published work see [https://doi.org/10.1093/geront/gnx175].

dementia unit when transferring from hospital to a nursing home. This carer phoned "up the chain" within the government to advocate for appropriate placement for her mother, and was eventually successful.

\section{Understanding System Navigation Outcomes: a Structural Burden Lens}

The analytic lens of structural burden illuminates how navigational work is generated by structural aspects of formal care systems. Participants' experiences indicated several contextual features of formal services: a lack of clear and transparent information about formal services and resources; low permeability and gatekeeping; bureaucratic complexity; fragmentation and a lack of coordination; and services that are unresponsive to family needs and circumstances. These features generate structural burden for carers by requiring increasing levels of navigational work, and making the nature of navigational work increasingly challenging.

Participants frequently characterized health and social care systems as opaque, mysterious, and lacking transparency. Overcoming barriers to accessing care was another common concern and source of struggle and work (characterized elsewhere as features of systems with low permeability: Dixon Woods et al. 2006). Lastly, systems perceived as poorly functioning - involving duplication, inefficiency, a lack of coordination, errors, excessive bureaucracy and unmet needs - were also a frequently mentioned source of carer struggle and navigational work. This was encapsulated by one carer who stated that the system of care for older adults is "by far the most difficult system I've ever had to navigate...it's complicated. It's so much more complicated than I think it needs to be."

In this section, we draw on participant data to explore how navigation-related structural burden may be connected to carer outcomes. Most directly, structural features of formal care systems contribute to burden by making additional time demands on family carers; carers frequently mentioned the amount of time required by navigational work. In addition, navigation was clearly experienced as stressful or challenging by many participants. As one carer stated, "the system certainly does not make it easy... It adds a lot of stress to [caregiving]." When carers recounted difficult navigation experiences in their interviews, our analysis indicated that these experiences, and their interpretation by carers, were connected to personal emotional distress during the navigational period, and in some cases, to longer-lasting system dissatisfaction.

In particular, when access to information about services was a problem, systems were interpreted as mysterious, and participants commonly described feeling lost, uncertain and confused. One daughter who struggled to access home care for her mother explained how fragmented services generated confusion:

There's not a single point of entry. You're getting in there from your physician, from a hospital, from like a whole bunch of different routes and that for me feels just like... it's like you're in an underground shopping centre where you lose your sense of direction. You can't figure out which 
This document is the author's version of an accepted manuscript of a published work that appeared in final form in The Gerontologist, copyright (C) Oxford University Press after peer review and technical editing by the publisher. To access the final edited and published work see [https://doi.org/10.1093/geront/gnx175].

is the exit and you have no idea if you take that particular hallway if you're going to emerge where you think you're going to because there's so many ways to get into it.

One co-resident daughter was concerned that her mother would eventually need to be institutionalized, but despite having done some research, she expressed distress over her confusion about how and when to initiate the process of getting formal support for her mother:

...because don't you need like a recommendation to get the homecare? So I don't know how you get a recommendation and then you get the homecare and then you get the paneling. It's like this weird process where like I can't initiate it so... (crying) I'm sorry.

The absence of accessible, clearly written guidelines about services and resources was connected to frustration and the sense of missing important information:

Like you really need like a 'one-stop shop.' It just seems like, health is over here and finances is there and there's this huge disconnect and everybody seems to be figuring it out for themselves and everybody is working from different information, I find. It's nice to have friends because they can share your information but even then you don't know if you're missing something and it's frustrating.

Anger and frustration emerged as the most common emotional response to the time and hassle involved in system navigation. These emotions arose in particular when carers believed that the work they were required to do should not be their primary responsibility, and that this work and associated stress originated from poor system function, callous and unkind gatekeepers, bureaucracy or policies perceived as trivial, inadequate communication, and general incompetence.

One participant described such aggravation and frustration when playing "telephone tag" and being shuffled between multiple contact persons when she had a question about her grandmother's care, stating: "I hate having to go through 18 doors when I can go through maybe one; at the most two right. It's time consuming and I don't have time." Another bereaved daughter stated: "It's been an education and it is one that ticks me off because, like really, I didn't go to med school. Somebody else can do this." Another daughter, after recounting her struggles securing her father a place in his preferred choice of nursing home, described not only her frustration, but distress: "the staff and structure and things are broken. So because of it, we are having to put all this time and energy in. I think we did not have a day for six weeks when I wasn't crying because it was so stressful."

Carers also tended to report frustration and disappointment when they learned about key pieces of information accidentally or randomly, or were successful in navigating only through trial and error. For instance, this included a carer who expressed 
This document is the author's version of an accepted manuscript of a published work that appeared in final form in The Gerontologist, copyright (C) Oxford University Press after peer review and technical editing by the publisher. To access the final edited and published work see [https://doi.org/10.1093/geront/gnx175].

her frustration that she only recently, and "randomly," learned that her 88 year old mother qualified for a senior's rate account at the bank, with no monthly fee, after caring for her for some time; her frustration here was targeted at the numerous bank tellers who failed to communicate this information to her previously. Likewise, a bereaved carer described her lengthy hunt to find specialized adaptive clothing for her mother with dementia. Her mother lived in a nursing home, and she expressed frustration that she had to spend time searching for information about where to purchase this clothing because none of the staff had appropriate knowledge. She added: "it took me three months to finally find the right things. You spend hours looking. So that was a stressful experience."

Indeed, a few carers reflected on the consequences of their navigational work, and in some cases, this also generated feelings of guilt. For example, one daughter believed she could have delayed institutionalizing her father if she had known about community supports. She regretted not questioning further: "I didn't push hard enough I think. I think I didn't."

Carers also connected their system navigation experiences to feelings of exhaustion and being overwhelmed. For instance, one participant explained how her plans and schedules changed from one day to the next, and she constantly felt short on both time and energy when coordinating care for her grandmother: 'I'm on 'auto-pilot' a lot because my brain is in so many places". As a result, she found that she had not had the time or space to process her recent grief over the loss of her mother, and reported feeling isolated and alone.

Several participants referred to the emotional energy they expended when they believed they had to "fight" providers for access to help or to ensure the quality of care. This was especially difficult for carers who found conflict itself, and being assertive, a stressful experience, suggesting that structural burden may be exacerbated for these individuals. As an example, one participant explained her struggles to set up a doctor's appointment:

I work in customer service and I don't like being a bitch to other people because I don't like it when it happens to me. But at this point I've been calling you guys for three days. You said you'd call me back. You don't call me back. Now I'm getting mad at the receptionist and I want to speak with somebody because I am so fed up with this.

Other participants emphasized the importance of balancing assertiveness with being 'nice' and even 'charming' in interactions with providers, and sought to avoid being stigmatized as uncooperative or difficult, which they believed could hinder their attempts to access resources. For example, one participant described the balancing act of managing relationships with nursing home staff to ensure her mother received quality care: 
This document is the author's version of an accepted manuscript of a published work that appeared in final form in The Gerontologist, copyright (C) Oxford University Press after peer review and technical editing by the publisher. To access the final edited and published work see [https://doi.org/10.1093/geront/gnx175].

\begin{abstract}
...the delicate balance between being pushy and being supportive and adversarial and [yet] cooperative; you sometimes have to step over the line a bit and then mend those fences to maintain the cordial relationship, because you gain nothing from having an adversarial relationship with the people who are caring for your loved one.
\end{abstract}

Emotional labour thus appears implicated in the work of system navigation. When faced with obstacles in accessing services, it was difficult for some carers to suppress their anger, even as they tried to empathize with the heavy workloads and constraints of individual workers.

Our analysis also suggests an indirect route through which formal care systems generate structural caring burden, by influencing the need for, and difficulty of navigational work. Although some carers recounted stories of their eventual success in securing services for care recipients, we also heard stories about a lack of access, "dead ends", and giving up. This quite obviously generated frustration (as expressed in interviews), yet may also have implications for carer outcomes in ways in which participants were as yet unaware, since services for older adults often indirectly help carers. An individual carer's success or failure at navigation shapes the care pathways of older adults, which in turn has implications for carer burden.

A few carers also expressed becoming discouraged by the difficulties of system navigation. For example, one carer cited her confusion with the waitlisting process for a nursing home as a reason for her delays in initiating the process ("I'm partly dealing with that by avoiding it"). In addition, two carers stated that they were postponing applying for a federal tax credit because they were overwhelmed by the complexity of the application; another carer cited the complexity involved in a direct-payments home care program as the reason she did not apply ("I can't do it because it involves bookkeeping and stuff like that."). In consideration of these carers, as well as those who expressed not even knowing where to begin to access services, we need to envision structural burden as a longer-term process that evolves over time with implications for caring careers.

\title{
Discussion and Implications
}

When older adults access formal services, it is generally believed that those services alleviate carer burden and enhance wellbeing. Our data suggest that ironically, the process of accessing and receiving resources can generate an additional form of burden that is structural in origin. In other words, challenges involved in learning about, accessing, and coordinating formal help may exacerbate carer burden even as the same resources help to alleviate other forms of burden.

We found that burden manifested through the considerable time and energy required to do system navigation, as well as through the difficult emotions generated by this work (most notably confusion, frustration, and feeling overwhelmed), often related to interactions with formal providers. In this regard, emotional labour is an often overlooked but important cost of system navigation, and the consequences of this work need to be 
This document is the author's version of an accepted manuscript of a published work that appeared in final form in The Gerontologist, copyright (C) Oxford University Press after peer review and technical editing by the publisher. To access the final edited and published work see [https://doi.org/10.1093/geront/gnx175].

examined more comprehensively in future research. Lastly, our findings indicate the need for more research to examine how structural burden may discourage carers from pursuing system navigation, how this process shapes service utilization, and the potential implications for both older adults and their carers.

In common with other research, our findings indicate that navigating access to formal systems may be easier for carers with more expertise and confidence (Wuest, 2000), and with more extensive social networks and cultural health capital (Shim, 2010). In contrast, navigation may be more challenging for new immigrants (Koehn et al., 2009) and when care recipients have multi-morbidity (Ravenscroft, 2010); in these and similar ways, structural burden can exacerbate inequities experienced by carers and care recipients (Taylor and Quesnel-Vallée, 2017). One of the limitations of the present study was that participants tended to have comfortable incomes and high levels of education; there was under-representation of structurally disadvantaged groups of carers within the province, and rural dwellers. The data thus offer less insight into how navigational challenges can interact with socio-economic disadvantage to generate inequities over time. Future research needs to explore this issue in particular.

Our research does, however, raise two important questions. First, how can we make navigation easier? Second, how can we mitigate the need for navigational work in the first place? Regarding the first question, carer-friendly systems should inform carers about available services and resources, help carers interpret and apply to programs, and generally provide navigational support (MacCourt \& Krawczyk, 2012). Our data indicate that navigation can be particularly challenging in the absence of information; however, greater transparency is not an easy fix. Service information may be unhelpful when it is "undigested, bureaucratized, and impersonal" (Bookman \& Harrington, 2007: p.1020), and long lists of services might overwhelm some carers (Mastel-Smith \& StanleyHermanns, 2012). Clear and consistent information about formal resources and services should be available in multiple formats, from multiple agencies, and provided directly to carers.

Providing information alone may be insufficient, and carers may need guidance through the process of accessing care. Facilitating access is often part of the role of case managers, social workers, or voluntary agencies (Carstairs \& Keon, 2009); however, many lack the time for in-depth navigational casework with families, and may be unable to help with advocacy. As case managers and social workers become more time-pressed, some organizations may prefer to develop specialized formal navigators. These roles, usually restricted to specific services, have been shown to be beneficial in reducing barriers for patients (Bradford, Coleman, \& Cunningham, 2007; Colombo et al., 2011; Corrigan et al., 2014; Manderson et al., 2012; Robinson-White et al., 2010). We know little, however, about whether and how such interventions might also reduce or prevent carer burden. Further, although formalized navigators may engage in direct case management, there is some indication that a dominant approach is simply to train carers to better manage the work of navigation through education and skill development (e.g., Duggleby et al., 2016, Bradford et al., 2007). Whether carers wish to do navigational 
This document is the author's version of an accepted manuscript of a published work that appeared in final form in The Gerontologist, copyright (C) Oxford University Press after peer review and technical editing by the publisher. To access the final edited and published work see [https://doi.org/10.1093/geront/gnx175].

work is rarely questioned, nor is it acknowledged that marginalized carers may be disadvantaged by a "hands-off" approach.

A fundamental improvement would be to reduce the extent and complexity of system navigation work in the first place; a preventive approach could include streamlined application processes, transparent waitlisting, extended roles for providers in coordination, and so on. We also need to critically reflect on how a focus on system navigation can detract attention from the availability of formal care services. Changes to the financing and delivery of public care services over the last several decades in many industrialized nations have constrained formal services from meeting older adults' needs. Thus, although a lack of service information is part of the problem, scarce resources are a closely related concern (Bookman \& Harrington, 2007) generating more restrictive eligibility criteria and increasing the challenges for carers trying to access services. This is an indirect contributor to structural burden and difficult to measure, but should not be ignored.

Our findings should be confirmed in larger and more representative carer samples, and in other Canadian provinces as well as international settings. Although a lack of transparency, fragmentation, rigidity, and complex bureaucracies are systemic features of many health and social care systems for older adults across regions, it is possible that navigational challenges and resulting structural burden may differ due to differing governmental approaches and policies which shape the level and quality of services, as well as the extent to which these are available and affordable for families.

Future research could examine the effects of navigational interventions on carer outcomes and compare different navigation approaches or roles. Research is also needed to identify particular carer groups that face greater structural burden. Lastly, longitudinal research could examine how navigational work, and thus structural burden, varies in intensity and complexity over time.

The concept of caregiver burden has been critiqued for limiting the focus of research and intervention to the caregiver-care recipient dyad, rather than broader material and organizational arrangements and practices shaping carers' daily lives (Purkis $\&$ Ceci, 2014). We propose that both system navigation and structural burden should be understood as public, structural issues, rather than solely problems of individuals or a lack of skills. A carer-friendly health care system needs to prioritize issues of fragmentation, lack of information, and barriers to access to care for older adults; addressing these issues can prevent and mitigate carer burden.

\section{Conflict of Interest}

We have no conflict of interest to declare.

\section{References}


This document is the author's version of an accepted manuscript of a published work that appeared in final form in The Gerontologist, copyright (C) Oxford University Press after peer review and technical editing by the publisher. To access the final edited and published work see [https://doi.org/10.1093/geront/gnx175].

Armstrong, P., \& Armstrong, H. (2005). Public and private: implications for care work. The Sociological Review, 53(Sup2), 167-187. doi: 10.1111/j.1467954X.2005.00579.x

Bookman, A., \& Harrington, M. (2007). Family caregivers: a shadow workforce in the geriatric health care system? Journal of Health Politics, Policy and Law, 32(6), 1005-1041.doi: 10.1215/03616878-2007-040

Bradford, J.B., Coleman, S., \& Cunningham, W. (2007). HIV system navigation: An emerging model to improve HIV care access. AIDS Patient Care and STDs. 21(s1), S-49-S-58. doi:10.1089/apc.2007.9987

Braun, V., \& Clarke, V. (2006). Using thematic analysis in psychology. Qualitative research in psychology, 3(2), 77-101.

Carstairs, S., \& Keon, W.J. (2009). Canada's Aging Population: Seizing the Opportunity: Special Senate Committee on Aging Final Report. Ontario, Canada. http://www.parl.gc.ca/Content/SEN/Committee/402/agei/rep/AgingFinalReporte.pdf

Colombo, F., Nozal-Llena, A., Mercier, J., \& Tjadens, F. (2011). Help wanted? Providing and paying for long-term care. OECD Health Policy Studies, OECD Publishing. Retrieved from http://www.oecd.org/els/healthsystems/helpwantedprovidingandpayingforlong-termcare.htm

Corrigan, P.W., Pickett, S., Batia, K., \& Michaels, P.J. (2014). Peer navigators and integrated care to address ethnic health disparities of people with serious mental illness. Social Work in Public Health. 29(6), 581-593. doi: 10.1080/19371918.2014.893854

Dixon-Woods, M., Kirk, M. D., Agarwal, M. S., Annandale, E., Arthur, T., Harvey, J., Hsu, R., Katbamna, S., Olsen, R., \& Smith, L. 2005. Vulnerable Groups and Access to_Health Care: A Critical Interpretive Review. National Co-ordinating Centre for NHS Service_Delivery and Organisation, London. Accessed 20 February 2008 at: http://www.menshealthforum.org.uk/uploaded_files/SDOvulnerablegroups2005.p df

Dohan, D., \& Schrag, D. (2005). Using navigators to improve care of underserved patients: current practices and approaches. Cancer, 104(4), 848-55. doi: $10.1002 /$ cncr.21214

Duggleby, W., Robinson, C.A., Kaasalainen, S., Pesut, B., Nekolaichuk, C., MacLeod, R., et al. (2016). Developing navigation competencies to care for older rural adults with advanced illness. Canadian Journal on Aging, 35(2), 206-14. doi: $10.1017 / \mathrm{S} 0714980816000131$

Farran, C.J., Loukissa, D., Perraud, S., \& Paun, O. (2004). Alzheimer's disease caregiving information and skills. Part II: Family caregiver issues and concerns. Research in Nursing and Health, 27(1), 40-51. doi: 10.1002/nur.20006 
This document is the author's version of an accepted manuscript of a published work that appeared in final form in The Gerontologist, copyright (C) Oxford University Press after peer review and technical editing by the publisher. To access the final edited and published work see [https://doi.org/10.1093/geront/gnx175].

Funk, L.M. (2012). Manitoba Caregiver Consultation Final Report. Seniors and Healthy Aging Secretariat, Ministry of Healthy Living, Seniors and Consumer Affairs. Winnipeg, MB. 44 pages. Accessed August 31, 2015 at: http://www.gov.mb.ca/shas/publications/reports.html

Funk, L.M., Stajduhar, K.I., \& Outcalt, L. (2015). What family caregivers learn when providing care at the end of life: a qualitative secondary analysis of multiple datasets. Palliative and Supportive Care, 13(3), 425-33. doi: 10.1017/S1478951513001168

Koehn, S. (2009). Negotiating candidacy: ethnic minority seniors' access to care. Ageing and Society, 29(4), 585-608. doi: 10.1017/S0144686X08007952

MacCourt, P., \& Krawczyk, M. (2012). Supporting the Caregivers of Seniors through Policy - The Caregiver Policy Lens. Vancouver, British Columbia: British Columbia Psychogeriatric Association.

Manderson, B., McMurray, J., Piraino, E., \& Stolee, P. (2012). Navigation roles support chronically ill older adults through healthcare transitions: a systematic review of the literature. Health and Social Care in the Community, 20(2), 113-127. doi: 10.1111/j.1365-2524.2011.01032.x

Martinez-Donate, A.P., Halverson, J., Simon, N.J., Schaaf Strickland, J., Trentham-Dietz, A., \& Smith, P.D., et al. (2013). Identifying health literacy and health system navigation needs among rural cancer patients: findings from the Rural Oncology Literacy Enhancement Study. Journal of Cancer Education, 28(3), 573-581. doi: $10.1007 / \mathrm{s} 13187-013-0505-\mathrm{x}$

Mastel-Smith, B., \& Stanley-Hermanns, M. (2012). "It's like we're grasping at anything": caregivers' education needs and preferred learning methods. Qualitative Health Research, 22(7), 1007-1015. doi: 10.1177/1049732312443739.

Neufeld, A., Harrison, M., Stewart, M.J., Hughes, K.D., \& Spitzer, D. (2002). Immigrant women: making connections to community resources for support in family caregiving. Qualitative Health Research, 12(6), 751-768. doi: 10.1177/104973230201200603

Patton, M. Q. (1990). Qualitative evaluation and research methods. Bevery Hills, CA: Sage Publications.

Peckham, A., Williams, A.P., \& Neysmith, S. (2014). Balancing formal and informal care for older persons: how case managers respond. Canadian Journal on Aging, 33(2), 123-136. doi: 10.1017/S0714980814000105

Penning, M. (2002). Hydra revisited: Substituting formal for self- and informal in-home care among older adults with disabilities. Gerontologist, 42(1), 4-16. doi: 10.1093/geront/42.1.4

Purkis, M.E., \& Ceci, C. (2014). Problematising care burden research. Ageing and Society, 35(7), 1-19. doi: 10.1017/S0144686X14000269 
This document is the author's version of an accepted manuscript of a published work that appeared in final form in The Gerontologist, copyright (C) Oxford University Press after peer review and technical editing by the publisher. To access the final edited and published work see [https://doi.org/10.1093/geront/gnx175].

Ravenscroft, E. (2010). Navigating the health care system: insights from consumers with multi-morbidity. Journal of Nursing and Healthcare of Chronic Illness, 2(3), 215-224. doi: 10.1111/j.1752-9824.2010.01063.x

Robinson-White, S., Conroy, B., Slavish, K., \& Rosenzweigh, M. (2010). Patient navigation in breast cancer: a systematic review. Cancer Nursing, 33(2), 127-140. doi: 10.1097/NCC.0b013e3181c40401

Rosenthal, C.J., Martin-Matthews, A., \& Keefe, N.M. (2007). Care management and care provision for older relatives amongst employed informal caregivers. Ageing and Society, 27(5), 755-778. doi: 10.1017/S0144686X07005995

Schubart, J.R., Kinzie, M.B., \& Farace, E. (2008). Caring for the brain tumor patient: family caregiver burden and unmet needs. Neuro-Oncology, 10(1), 61-72. doi: $10.1215 / 15228517-2007-040$

Shim, J.K. (2010). Cultural health capital: A theoretical approach to understanding health care interactions and the dynamics of unequal treatment. Journal of Health and Social Behavior, 51(1), 1-15. doi: 10.1177/0022146509361185

Taylor, M.G., \& Quesnel-Vallée, A. (2017) The structural burden of caregiving: shared challenges in the United States and Canada. The Gerontologist, 57(1), 19-25. doi: 10.1093/geront/gnw 102

Williams, A., Crooks, V.A., Giesbrecht, M., \& Dykeman, S. (2010). Evaluating Canada's Compassionate Care Benefit from the Perspective of Family Caregivers. Hamilton, Ontario. Accessed January 12017 at: http://www.coag.uvic.ca/eolcare/documents/CCB\%20evaluation\%20final\%20report\% 20-\%20English.pdf

Wuest, J. (2000). Negotiating with helping systems: an example of grounded theory evolving through emergent fit. Qualitative Health Research, 10(1), 51-70. doi: $10.1177 / 104973200129118246$ 
This document is the author's version of an accepted manuscript of a published work that appeared in final form in The Gerontologist, copyright (C) Oxford University Press after peer review and technical editing by the publisher. To access the final edited and published work see [https://doi.org/10.1093/geront/gnx175].

Table 1. Demographic Characteristics of Participants

\begin{tabular}{|c|c|c|}
\hline \multirow{2}{*}{ Age } & Range & $25-90$ years \\
\hline & Average & 57.25 years \\
\hline \multirow{3}{*}{$\begin{array}{l}\text { Length of time } \\
\text { providing care }\end{array}$} & Range & 6 months -30 years \\
\hline & Average & 8.45 years \\
\hline & & Frequency $(\%)$ \\
\hline \multirow{3}{*}{ Gender } & Female & $26(81.3 \%)$ \\
\hline & Male & $6(18.8 \%)$ \\
\hline & Single/never married & $7(21.9 \%)$ \\
\hline \multirow{3}{*}{ Marital status } & Widowed & $2(6.3 \%)$ \\
\hline & Separated/divorced & $7(21.9 \%)$ \\
\hline & Married/common-law & $16(50.0 \%)$ \\
\hline \multirow{5}{*}{ Education } & High school or less & $2(6.2 \%)$ \\
\hline & Some university, college or trade school & $11(34.4 \%)$ \\
\hline & Undergraduate degree & $13(40.6 \%)$ \\
\hline & Post graduate degree & $6(18.8 \%)$ \\
\hline & Full time & $17(53.2 \%)$ \\
\hline \multirow{3}{*}{ Employment status } & Part time/seasonal & $8(25.0 \%)$ \\
\hline & Retired & $4(12.5 \%)$ \\
\hline & Other (disability, never worked) & $3(9.4 \%)$ \\
\hline \multirow{2}{*}{$\begin{array}{l}\text { Visible minority } \\
\text { status }\end{array}$} & Caucasian & $26(81.3 \%)$ \\
\hline & Visible Minority & $6(18.8 \%)$ \\
\hline \multirow{4}{*}{$\begin{array}{l}\text { Average annual } \\
\text { household income }\end{array}$} & $\$ 39,000$ and under & $6(18.7 \%)$ \\
\hline & $\$ 40,000-\$ 79,000$ & $19(59.4 \%)$ \\
\hline & $\$ 80,000$ and up & $7(21.9 \%)$ \\
\hline & Mother & $16(50 \%)$ \\
\hline \multirow{4}{*}{$\begin{array}{l}\text { Care recipient's } \\
\text { relationship to } \\
\text { carer }\end{array}$} & Father & $7(21.9 \%)$ \\
\hline & Husband & $5(15.6 \%)$ \\
\hline & Wife & $2(6.3 \%)$ \\
\hline & Grandmother & $2(6.3 \%)$ \\
\hline \multirow{6}{*}{$\begin{array}{l}\text { Care recipient's } \\
\text { living situation }\end{array}$} & Co-resident with carer & $17(53.1 \%)$ \\
\hline & Assisted living or nursing home & $12(37.5 \%)$ \\
\hline & Living independently & $3(9.4 \%)$ \\
\hline & Dementia & $8(25.0 \%)$ \\
\hline & "Aging" & $5(15.6 \%)$ \\
\hline & Mobility impairment & $4(12.5 \%)$ \\
\hline \multirow{5}{*}{$\begin{array}{l}\text { Care recipient's } \\
\text { primary diagnosis }\end{array}$} & Stroke & $4(12.5 \%)$ \\
\hline & Other & $4(12.5 \%)$ \\
\hline & Cancer & $3(9.4 \%)$ \\
\hline & Chronic obstructive pulmonary disease & $2(6.3 \%)$ \\
\hline & Arthritis & $2(6.3 \%)$ \\
\hline
\end{tabular}


This document is the author's version of an accepted manuscript of a published work that appeared in final form in The Gerontologist, copyright (C) Oxford University Press after peer review and technical editing by the publisher. To access the final edited and published work see [https://doi.org/10.1093/geront/gnx175]. 